\title{
CLIMATOLOGIA DA PRECIPITAÇÃO NO MUNICÍPIO DO RIO DE JANEIRO
}

\author{
CLAUDINE PEREIRA DERECZYNSKI ${ }^{1}$, JULIANA SILVA DE OLIVEIRA ${ }^{2}$ E \\ CHRISTIANE OSÓRIO MACHADO²
}

\author{
${ }^{1}$ Universidade Federal do Rio de Janeiro - Instituto de Geociências - Departamento de Meteorologia, \\ Rio de Janeiro, RJ, Brasil. \\ ${ }^{2}$ Centro Federal de Educação Tecnológica Celso Suckow da Fonseca do Rio de Janeiro, \\ Coordenadoria de Meteorologia. Rio de Janeiro, RJ, Brasil.
}

\author{
claudine@acd.ufrj.br, juliana.cefetrj@gmail.com,chrisorio@gmail.com
}

Recebido Janeiro 2008 - Aceito Dezembro 2008

\begin{abstract}
RESUMO
Uma climatologia preliminar da precipitação no município do Rio de Janeiro é elaborada utilizando-se 10 anos de dados observados na rede de 30 postos pluviométricos da Fundação Geo-Rio. A distribuição espacial do total pluviométrico anual médio mostra que os máximos concentram-se junto aos três maciços existentes na cidade: na Serra da Carioca $(2200 \mathrm{~mm})$ na Serra do Mendanha (1400 mm) e na Serra Geral de Guaratiba (1200 mm). Tais valores reduzem-se em direção às planícies, sendo um mínimo de 900 mm observado na Zona Norte da cidade. A estação Sumaré destaca-se por seus elevados índices pluviométricos durante todo o ano, especialmente em setembro quando a precipitação média mensal $(297,5 \mathrm{~mm})$ chega a ser cerca de sete vezes maior do que a dos postos localizados na Zona Norte. No Sumaré são observados em média 119 dias de chuva ao ano, enquanto, por exemplo, na Penha ocorre chuva em apenas 86 dias. A análise dos eventos de chuvas intensas indicou que $77 \%$ dos 160 casos selecionados, foram provocados por sistemas frontais, que ocorrem durante todo o ano, com menor freqüência no inverno. Eventos associados à Zona de Convergência do Atlântico Sul $(13 \%)$ e sistemas convectivos de mesoescala ( $8 \%)$ predominam no verão. Chuvas intensas geradas por efeito de circulação marítima ocorreram em apenas $2 \%$ dos casos.
\end{abstract}

Palavras-chave: precipitação, climatologia, eventos extremos, Rio de Janeiro

\begin{abstract}
PRECIPITATION CLIMATOLOGY OF THE CITY OF RIO DE JANEIRO
A preliminary 10-year precipitation climatology of Rio de Janeiro is elaborated by means of the Geo-Rio Foundation rain gauge network. The spatial distribution of annual precipitation shows that the maxima coincide with the three hills in the city: Carioca $(2200 \mathrm{~mm})$, Mendanha $(1400 \mathrm{~mm})$ and Geral de Guaratiba $(1200 \mathrm{~mm}$ ). The precipitation values decrease toward the plain, with minimum values in the Northern Zone. The precipitation is greater at the Sumare gauge than in all the other places throughout the year, especially in September when the monthly mean precipitation (297.5 $\mathrm{mm}$ ) is seven times greater than the precipitation in other Northern Zone stations. For example, rain occurs 119 days per year at Sumaré; at Penha it occurs only 86 days per year. The anaylsis of the intense events shows that $77 \%$ of the 160 selected events were caused by frontal systems, which occur throughout the year, though less frequently in winter. South Atlantic Convergence Zone events (13\%) and Mesoscale Convective Systems (8\%) occurred predominantly in summer. Rainfall caused by a sea breeze circulation occurred only in $2 \%$ of cases.
\end{abstract}

Keywords: precipitation, climatology, extreme events, Rio de Janeiro 


\section{INTRODUÇÃO}

A cidade do Rio de Janeiro é considerada a segunda maior mancha urbana do Brasil, um dos maiores centros econômicos e culturais da América Latina. Em sua área territorial de 1.224,56 $\mathrm{km}^{2}$, sendo 70,7\% urbanizada (IPP, 2005), residem 6.093.472 habitantes (IBGE, 2007). O município do Rio de Janeiro recebe anualmente mais de 1,4 milhão de turistas estrangeiros e cerca de 3 milhões de visitantes por ano no turismo interno (http://www.brasilchannel.com.br). Nesse sentido, devido à importância da cidade, o conhecimento da climatologia da precipitação é de extrema utilidade para diversas atividades relacionadas ao comércio, indústria e turismo, além do próprio planejamento urbano.

A cidade desenvolve-se ao redor do Maciço da Tijuca, que a divide em "Zona Norte" e "Zona Sul". O relevo acidentado e diversificado da cidade, com mais dois maciços, GericinóMendanha ao norte e da Pedra Branca à oeste, contribui para a grande variabilidade espacial da precipitação. Neste trabalho elabora-se uma análise climatológica da precipitação sobre a cidade do Rio de Janeiro, utilizando a base de dez anos de dados da Fundação Instituto de Geotécnica do Município do Rio de Janeiro (Geo-Rio) para o período de 1997 a 2006. Os objetivos principais do trabalho são conhecer a variabilidade espacial e temporal da precipitação e identificar os sistemas meteorológicos responsáveis pelas chuvas intensas que ocorrem na cidade.

Nos poucos trabalhos e distintos conjuntos de dados de precipitação disponíveis para a cidade do Rio de Janeiro, a distribuição dos pluviômetros é irregular e de baixa densidade, decorrente da ausência de uma política de monitoramento meteorológico municipal. Nesse sentido este trabalho contribui para o entendimento da climatologia da precipitação no município.

No item 2 é feita uma revisão da literatura sobre a climatologia do município do Rio de Janeiro. A metodologia e os dados utilizados são apresentados no item 3 . No item 4 estão os resultados, sub-divididos na climatologia da precipitação sobre o município do Rio de Janeiro e em taxas de chuvas intensas. Nos itens 5, 6 e 7 são apresentados, respectivamente, as conclusões, os agradecimentos e as referências bibliográficas.

\section{CLIMATOLOGIA DO MUNICÍPIO DO RIO DE JANEIRO}

A cidade do Rio de Janeiro (RJ) localizada entre os paralelos $22^{\circ} 45^{\prime} 05^{\prime \prime} \mathrm{S}$ e $23^{\circ} 04^{\prime} 10^{\prime \prime} \mathrm{S}$ e os meridianos $43^{\circ}$

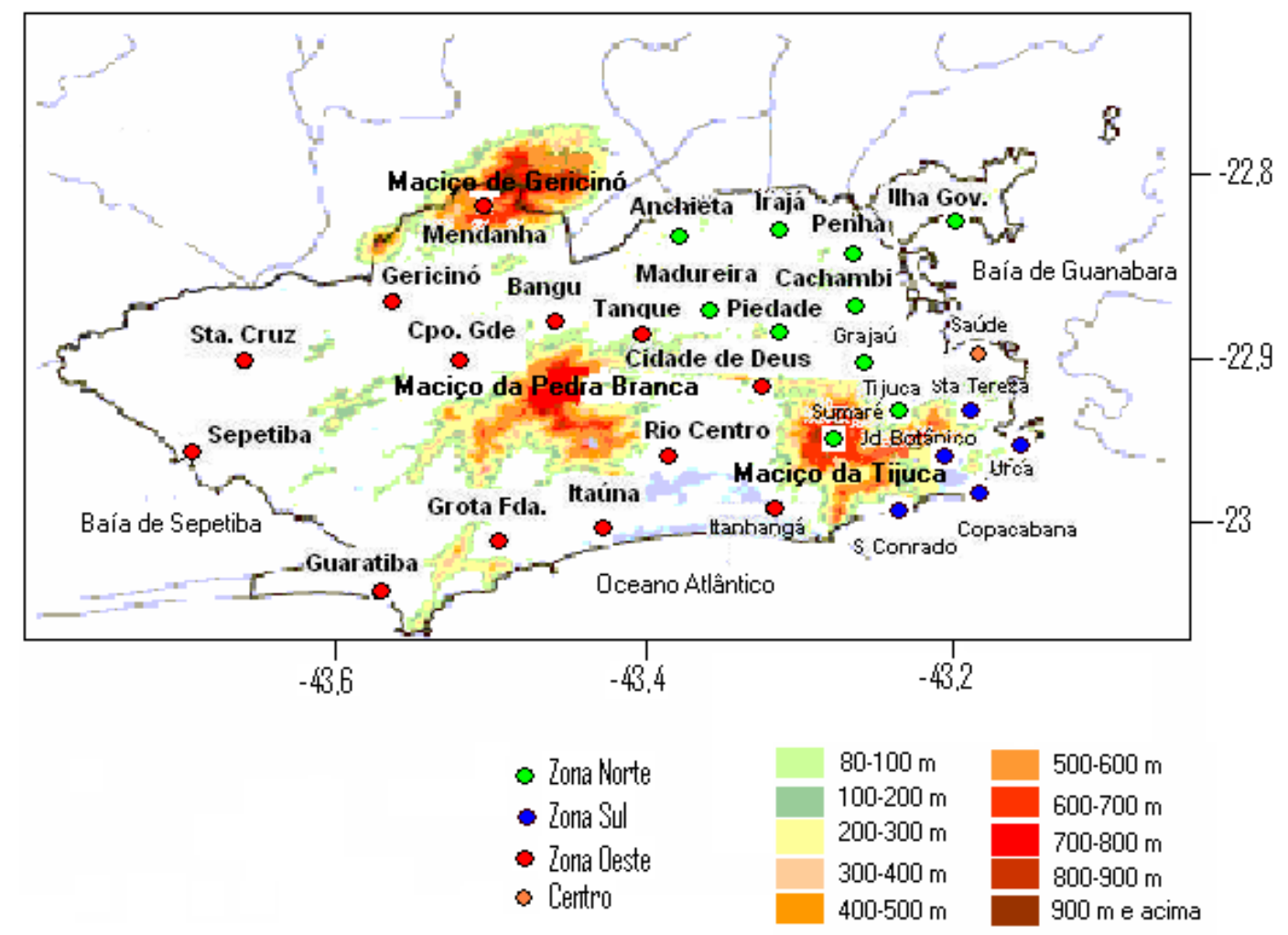

Figura 1 - Topografia da cidade do Rio de Janeiro e localização dos postos pluviométricos da Fundação Geo-Rio utilizadas no trabalho (Fonte: Adaptado de MMA, 2002). 


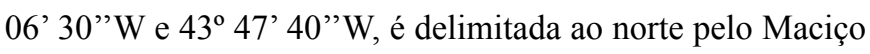
Gericinó-Mendanha, ao sul pelo Oceano Atlântico, a leste pela Baía de Guanabara e a oeste pela baía de Sepetiba (Figura 1). Entre as suas características físicas, a topografia acidentada e extremamente diversa se sobressai, marcada pela formação de maciços, cujas encostas originalmente cobertas por florestas da Mata Atlântica, apresentam altos graus de declividade. Os maciços principais são o do Gericinó-Mendanha, ao norte, onde se encontram as Serras do Mendanha e de Gericinó, com o Pico do Guandu localizado a 964 m; o maciço da Tijuca, a leste, com o Pico da Tijuca localizado a $1022 \mathrm{~m}$ de altitude e o maciço da Pedra Branca a oeste, onde se localiza o ponto mais elevado da cidade, o Pico da Pedra Branca (1025 m). Entretanto, a forma de relevo mais típica da cidade é a planície, que representa $64 \%$ do território municipal, denominada de baixada, possuindo uma variação de altitude que não ultrapassa os $20 \mathrm{~m}$ acima do nível médio do mar. Da área territorial total, aproximadamente $20 \%$, encontra-se numa altitude superior a 100 m (MMA, 2002).

O Estado do Rio de Janeiro permanece sob a influência do Anticiclone Subtropical do Atlântico Sul (ASAS) na maior parte do tempo. Tal sistema é responsável pelas condições de céu claro ou com pouca nebulosidade e ventos de direção nordeste de fraca intensidade que predominam no nordeste do Estado (FIDERJ, 1978). Esta situação de estabilidade sobre o Estado é interrompida pela chegada de sistemas transientes, tais como: sistemas frontais (SFs), ciclones extratropicais, vórtices ciclônicos dos altos níveis de origem subtropical, sistemas convectivos de mesoescala (SCMs) e outros sistemas que promovem o aumento da nebulosidade, a ocorrência de precipitação e a intensificação dos ventos. Em especial, durante os meses de novembro a março é comum o estabelecimento da Zona de Convergência do Atlântico Sul (ZCAS) que se caracteriza por uma banda de nebulosidade convectiva, estendendo-se em geral desde a Amazônia, até o Oceano Atlântico, numa direção noroeste-sudeste (Kousky, 1988). Este sistema é típico dos meses de verão, quando a convecção tropical mais acentuada contribui para a geração e manutenção do fenômeno (Kodama, 1992).

Sobre o Estado do Rio de Janeiro, no inverno e na primavera verifica-se, em média, a passagem de quatro SFs por mês, ou seja, aproximadamente um por semana. No verão e outono ocorre uma pequena redução em sua freqüência, observando-se em torno de três SFs por mês (Oliveira, 1986; Lemos e Calbete, 1996 e Justi da Silva, 2003). De acordo com Oliveira (1986), apesar da menor freqüência de SFs atingindo a banda latitudinal entre 25 e $20^{\circ} \mathrm{S}$ durante o verão, nesta estação todos os SFs conseguem organizar a convecção no interior do continente, enquanto no inverno, dos quatro SFs apenas um organiza a convecção. De fato, a trajetória dos SFs sobre a América do Sul segue dois padrões bastante distintos ao longo do ano. A trajetória de verão é mais lenta e caracterizada por maior atividade convectiva devido às complexas interações entre os sistemas transientes de escala sinótica e os sistemas quase estacionários como a Alta da Bolívia e a ZCAS. No inverno os SFs deslocam-se mais rapidamente, em trajetórias mais zonais e não conseguem penetrar no interior do continente. Tais sistemas não induzem apreciável atividade convectiva sobre o Brasil central e o Sudeste do Brasil, mas ocasionalmente, provocam forte queda de temperatura, em tais regiões (Nobre et al., 1998).

Especificamente sobre a climatologia do município do Rio de Janeiro existem poucas referências utilizando-se longas séries de dados observacionais. Além disso, a maior parte dos trabalhos foi desenvolvida nas décadas de 1950 e 1970.

De acordo com Serra e Ratisbona (1957) e Serra (1970) os totais pluviométricos anuais sofrem elevação de $1200 \mathrm{~mm}$ junto ao litoral da Zona Sul da cidade até $1600 \mathrm{~mm}$ à barlavento do maciço da Tijuca. A partir deste máximo a precipitação diminui, chegando a $1000 \mathrm{~mm}$ na Zona Norte. Um segundo máximo de $1400 \mathrm{~mm}$ no extremo norte da cidade é observado próximo ao maciço Gericinó-Mendanha. Nas demais áreas da cidade a precipitação anual oscila entre 1200 e 1400 mm. Em janeiro, a precipitação é maior no extremo norte da cidade, chegando a $200 \mathrm{~mm}$ próximo ao maciço Gericinó-Mendanha, decai gradativamente em direção ao interior da cidade, com mínimo de $120 \mathrm{~mm}$ na Zona Norte e a partir daí se eleva até o litoral da Zona Sul, onde a precipitação chega a $160 \mathrm{~mm}$. Em julho, nota-se uma redução gradativa da precipitação, oscilando entre $100 \mathrm{~mm}$ na Zona Sul até $20 \mathrm{~mm}$ no extremo norte do município. Tais análises foram elaboradas considerando-se dados observacionais em 20 estações meteorológicas distribuídas de forma insatisfatória, com a maior parte no norte da cidade, somente a zona sul da cidade possuindo estações no litoral e sem qualquer posto na baixada de Jacarepaguá e nos maciços.

Com relação ao regime de ventos, a rosa anual do Observatório Central indica duas direções predominantes: a principal de SSE e a secundária de NW (Serra e Ratisbona, 1957). A velocidade média oscila entre $2,8 \mathrm{~m} \cdot \mathrm{s}^{-1}$ (de abril a julho) a 4,0 m.s $\mathrm{s}^{-1}$ (entre outubro e novembro). Em FIDERJ (1978) nota-se que os ventos sopram predominantemente de sudeste na estação Praça XV com intensidade entre 4 e 6 m.s. durante quase todo o ano, com exceção de junho e julho, quando a intensidade decai para $2-4 \mathrm{~m} \cdot \mathrm{s}^{-1}$. A segunda direção mais freqüente é de sul e a terceira de noroeste, com intensidade entre 2 e $4 \mathrm{~m} . \mathrm{s}^{-1}$ ao longo do ano. Isto demonstra que apesar de no Estado do Rio de Janeiro as direções nordeste e norte serem predominantes (FIDERJ, 1978), influenciadas pela circulação do ASAS , no município do Rio de Janeiro as brisas marítima e terrestre dominam a circulação local. Ventos de SW sopram no período da tarde e à noite, quando o continente se encontra 
mais aquecido, produzindo maiores intensidades. Ventos de NW (brisa terrestre) predominam na madrugada e manhã, períodos em que o continente se encontra menos aquecido, com intensidade inferior à brisa marítima (Serra, 1970).

Em Jourdan (2007) é elaborada uma caracterização dos ventos à superfície na Região Metropolitana do Rio de Janeiro, incluindo sete estações no município do Rio de Janeiro. Apesar das séries de dados horários serem relativamente curtas, com no máximo 6 anos de dados entre 2000 e 2006, importantes resultados foram obtidos. Em geral, no município predominam ventos de quadrante norte, que ocorrem na madrugada e manhã e de quadrante sul, que ocorrem nos períodos da tarde e noite, estes em geral mais intensos do que os ventos nas demais direções. Este aspecto sugere uma modulação através do mecanismo de brisa terrestre/marítima. Tal padrão se mantém ao longo do ano. Na primavera e verão, época em que o aquecimento da superfície continental é mais intenso, a intensidade e a freqüência dos ventos de quadrante sul aumentam em relação ao padrão anual. De acordo com o autor, um dos fatores que contribui para este fato seria a intensificação do gradiente horizontal de temperatura resultante do aumento do aquecimento diferenciado entre continente e oceano, induzindo uma intensificação da circulação da brisa marítima, enquanto no outono e inverno diminui a freqüência dos registros da direção sul e aumenta a freqüência dos ventos de norte.

\section{METODOLOGIA E DADOS}

Os dados de precipitação utilizados referem-se aos observados na rede pluviométrica instalada pela Fundação GeoRio no Município do Rio de Janeiro em setembro de 1996. A rede atual é composta de 32 postos pluviométricos automáticos, cujas informações, tais como localização, endereços e ficha técnica estão disponíveis em http://www2.rio.rj.gov.br/georio/site/ alerta/alerta.htm. Neste trabalho foram utilizados os dados de 30 postos (Figura 1), excluindo-se Laranjeiras e São Cristóvão que começaram a operar em setembro de 2000 . O período analisado estende-se de janeiro de 1997 à dezembro de 2006, obtendo-se 10 anos para análise.

A localização dos postos pluviométricos da Fundação Geo-Rio visa atender ao sistema de alerta de chuvas intensas, e as estações não são homogeneamente distribuídas. Nota-se na Figura 1 que em locais como, por exemplo, o Maciço da Pedra Branca, por se tratar de uma área de proteção ambiental onde há baixo risco de deslizamentos, não existem postos pluviométricos. Por outro lado, em torno do Maciço da Tijuca a concentração de postos é maior do que nas demais áreas da cidade.

Os totais pluviométricos diários foram calculados efetuando-se o total de precipitação em 24 horas, considerando o acumulado originalmente a cada 15 minutos, no intervalo entre as observações de $9 \mathrm{~h}$ e $15 \mathrm{~min}$ local (12:15 Z) do dia anterior e 9h local (12:00 Z) do referido dia.

A análise preliminar excluiu os totais pluviométricos mensais das estações meteorológicas em que o número de falhas nas observações foi superior a 120 horas no mês, o que corresponde a 5 dias de falhas. Os períodos desconsiderados na análise foram: a) 1997 - Anchieta, Santa Cruz e Sepetiba em setembro; Sepetiba em outubro e Guaratiba em novembro; b) 2000 - Itaúna e Campo Grande em outubro; Campo Grande em novembro; c) 2001 - todas as estações em janeiro e d) 2005 - Grota Funda, Guaratiba e Riocentro em abril e Campo Grande em maio.

Os totais mensais e anuais e as médias sazonais também foram calculados. As médias sazonais foram obtidas considerando-se para o verão o trimestre dezembrojaneiro-fevereiro, outono março-abril-maio, inverno junhojulho-agosto e primavera setembro-outubro-novembro. Os máximos absolutos em 15 e 30 minutos, 1 hora e 1 dia foram determinados, selecionando-se o maior valor dentre os 10 anos pesquisados para cada posto pluviométrico. No caso dos máximos de 30 minutos e 1 hora foram calculados os totais móveis. Para os máximos em 1 dia foram considerados os maiores totais pluviométricos diários, considerando-se a precipitação acumulada entre $12: 15 \mathrm{Z}$ do dia anterior e 12:00 $\mathrm{Z}$ do referido dia, como descrito anteriormente.

\subsection{Seleção dos Eventos de Precipitação Intensa}

Os eventos de precipitação intensa foram considerados como aqueles em que a precipitação diária fosse igual ou superior a $30,0 \mathrm{~mm}$, em pelo menos cinco estações pluviométricas. $\mathrm{O}$ valor limite de 30,0 mm foi adotado, pois a aplicação da técnica dos percentis a cada uma das estações, revelou que este valor representa um limite inferior para chuvas intensas na cidade. Para todos os postos pluviométricos os totais diários de precipitação correspondentes ao percentil 99 são superiores a $30,0 \mathrm{~mm}$. A escolha do número mínimo de localidades (no caso 5) com chuva superior a $30,0 \mathrm{~mm}$, foi feita nesta pesquisa para que fossem selecionados, além de eventos de escala sinótica, alguns eventos de mesoescala, tais como CM e SCMs. Limitando-se, por exemplo, em 10 o número de postos pluviométricos com chuva superior a 30,0 $\mathrm{mm}$ todos os casos de CM seriam excluídos, assim como mais da metade dos casos de SCM. Aumentando-se para 25 o número de postos pluviométricos com precipitação igual ou superior a $30,0 \mathrm{~mm}$ predominariam casos de SFs e ZCAS, com apenas um evento de SCM.

Adefinição de limiares de precipitação para a identificação de eventos de chuvas intensas é bastante variável. Konrad (1997) estudou 312 eventos de chuva intensa sobre o sudeste dos Estados Unidos, definindo evento extremo como aquele 
que produziu no mínimo $50 \mathrm{~mm}$ de precipitação em uma ou mais estações dentro de um período de 6 horas. Junker et al. (1999) fizeram uma climatologia sinótica de nove Estados do Meio Oeste dos Estados Unidos atingidos por eventos de chuva intensa no período de junho a setembro de 1993, selecionando os casos que contabilizaram mais do que $50 \mathrm{~mm}$ em 24 horas. Teixeira e Satyamurty (2007) adotaram como critério de seleção de casos de chuvas intensas na Região Sul do Brasil, eventos nos quais a isoieta de $50 \mathrm{~mm}$ em $24 \mathrm{~h}$ cobrisse uma área de no mínimo $10.000 \mathrm{~km}^{2}$. Liebmann et al. (2001) estudando a variabilidade interanual dos eventos de precipitação extrema

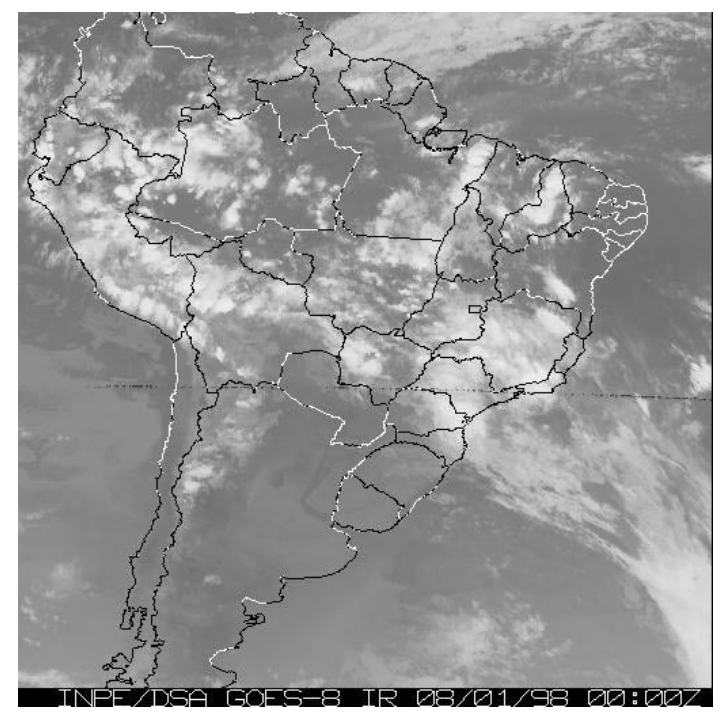

(a) SF - 08/01/98 - $00 \mathrm{Z}$

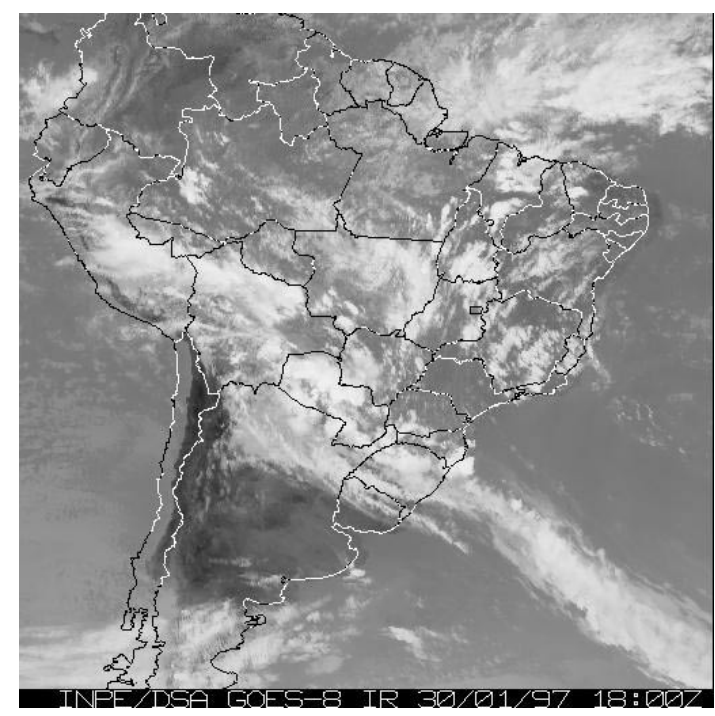

(c) SCM - 30/01/97 - $18 \mathrm{Z}$ diária no Estado de São Paulo, definem como evento extremo, aquele em que a precipitação diária excede uma porcentagem da sua média sazonal ou anual.

Após selecionados, os eventos foram classificados utilizando-se imagens de satélites nos canais visível e infravermelho e a revista Climanálise do CPTEC/INPE. Exemplos de casos de SF, ZCAS, SCM e CM são ilustrados na Figura 2, através da nebulosidade característica de tais sistemas nas imagens do satélite GOES-8, canal infravermelho.

Os SFs (Figura 2a ) são identificados numa imagem de satélite, por suas bandas distintivas de nebulosidade tipicamente

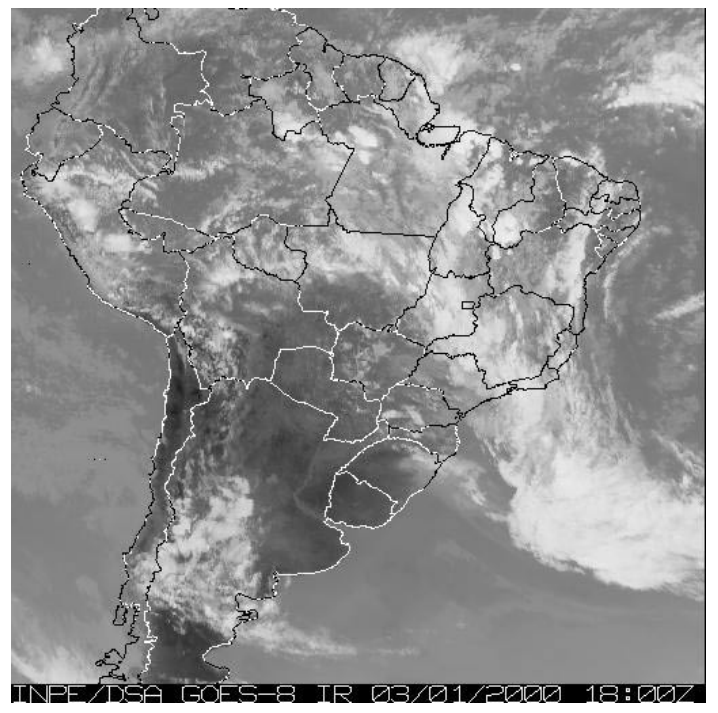

(b) ZCAS - 03/01/00-18 Z

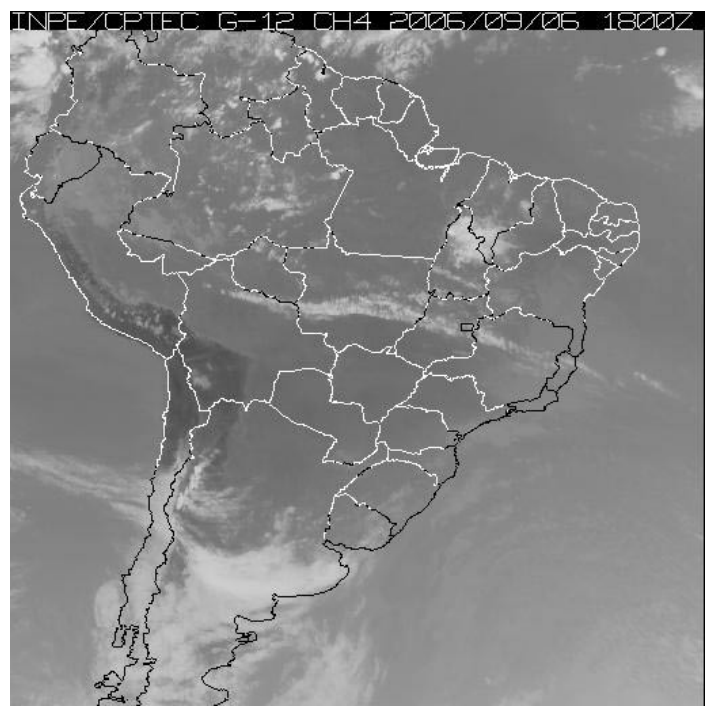

(d) $\mathrm{CM}-06 / 09 / 06-18 \mathrm{Z}$

Figura 2 - Imagens de satélite GOES-8 no canal infravermelho para exemplificar casos de: (a) SF (08/01/98 - 00Z); (b) ZCAS (03/01/00 - 18 Z); (c) SCM (30/01/97 - 18 Z) e (d) CM (06/09/09 - 18 Z). 
de grande desenvolvimento vertical ocorrendo ao longo de todo o ano.

A ZCAS (Figura 2b) é visível em imagens de satélite durante o verão como uma faixa persistente de nebulosidade orientada no sentido noroeste-sudeste, estendendo-se do sul da Amazônia até o Atlântico (Kousky, 1988). É importante ressaltar, que neste trabalho se a chuva intensa ocorrer na chegada do primeiro SF que irá iniciar o fenômeno ZCAS, ainda assim o sistema será classificado como SF. Outro ponto importante é que um evento pode se estender por mais de um dia, como por exemplo, o caso do evento de ZCAS de janeiro de 1997, onde foram observados três dias com chuvas iguais ou superiores a $30,0 \mathrm{~mm}$ em mais do que 5 postos pluviométricos.

Os SCMs (Figura 2c) podem ser identificados nas imagens de satélite como agrupamentos de nuvens cumulonimbus, que adquirem uma certa organização, sendo as linhas de instabilidade os tipos mais comuns de tempestades multicelulares. Vianello e Alves (1991) ressaltam a forma alongada na qual nuvens cumulos se desenvolvem e se deslocam, podendo resultar em chuvas intensas e localizadas, principalmente na época de verão do hemisfério sul, geralmente associadas à SFs. Neste estudo, verificou-se em vários eventos a intensificação da precipitação devido à presença de SCMs embebidos em SFs. Em todos esses casos, considera-se que o SF foi o sistema meteorológico gerador da precipitação. Contudo, existem casos, como os da Figura 2c, em que a linha de instabilidade ocorre antes da passagem do SF.

Os casos de precipitação provocada por efeito de circulação marítima (Figura 2d) são considerados, quando ocorre chuva fraca de origem estratiforme, devido ao transporte de umidade do oceano para o litoral, a partir da intensificação da brisa marítima. Em tais ocasiões predominam ventos de quadrante sul, convergência de umidade e fraco movimento ascendente sobre o município (Domingues e Dereczynski, 2005).

\section{RESULTADOS}

Neste item é feita inicialmente uma análise da distribuição espacial da precipitação sobre o município do Rio de Janeiro, considerando-se as médias sazonais e anual sobre um período de dez anos (1997-2006), obtidas a partir da rede de 30 pluviômetros da Fundação Geo-Rio. As precipitações médias mensais e a frequiência média de ocorrência de chuva ao longo do ano, sazonalmente e ao longo do dia são analisadas para algumas localidades selecionadas.

A seguir é elaborada uma estatística dos casos de chuvas intensas ocorridos na cidade durante o período em estudo, associando-se o sistema meteorológico responsável pela ocorrência de cada evento.

\subsection{Climatologia da Precipitação sobre o Município do Rio de Janeiro}

A Figura 3 apresenta a distribuição espacial da precipitação média (1997-2006) sobre a cidade do Rio de Janeiro, considerando-se os totais anuais e as médias mensais sazonais. Ressalta-se a presença de três máximos de precipitação, associados às três serras existentes na cidade: o primeiro junto à Serra da Carioca (no sudeste da cidade), onde se localiza a estação Sumaré, o segundo junto à Serra do Mendanha (no norte da cidade), onde se encontra a estação Mendanha, e o terceiro junto à Serra Geral de Guaratiba (no sudoeste da cidade), próximo à estação Grota Funda. Nas áreas de planície a precipitação é sempre inferior aos totais observados junto às serras mencionadas, destacando-se um mínimo de precipitação no extremo norte da cidade, onde se localizam as estações Irajá e Penha. Os sistemas transientes deslocando-se, em geral, de sul para norte e a presença da topografia forçam o ar úmido a se elevar à barlavento das serras. Este ar ascendente se resfria e se condensa, formando nuvens e chuva, produzindo-se então máximos de precipitação à barlavento das encostas. Após perder grande parte de sua umidade o ar desce as serras, sendo comprimido e aquecido, inibindo assim a formação de nuvens e consequentemente reduzindo-se a precipitação a sotavento das montanhas. Tal processo é amplificado pelo levantamento de ar úmido trazido pela brisa marítima que predomina no município.

A distribuição dos totais pluviométricos médios anuais (Figura 3a) indica um máximo de $2200 \mathrm{~mm}$ no Sumaré, outro de $1400 \mathrm{~mm}$ no Mendanha e o terceiro de $1200 \mathrm{~mm}$ na Grota Funda. Analisando-se a topografia da região (Figura 1), notase que a estação Grota Funda não está localizada na região de maior altitude da Serra Geral de Guaratiba, desta forma provavelmente a precipitação máxima deve ocorrer a nordeste deste posto pluviométrico, onde a altitude é mais elevada. No extremo norte da cidade, a precipitação é inferior às demais localidades do município, chegando a ser inferior a $1000 \mathrm{~mm}$ em Irajá $(905 \mathrm{~mm})$ e na Penha $(870 \mathrm{~mm})$. No oeste da cidade predominam valores entre 1000 e $1200 \mathrm{~mm}$, exceto em Bangu onde a precipitação é de $991 \mathrm{~mm}$.

De acordo com Serra (1970), o único máximo pluviométrico anual em destaque sobre o município seria o do maciço da Tijuca, com valores de $1600 \mathrm{~mm}$. Este valor é bastante inferior ao observado nesta climatologia de dez anos (2200 mm), o que se justifica pela baixa densidade de estações pluviométricas sobre a cidade, no referido trabalho. Serra afirma ainda que a precipitação anual na Zona Sul da cidade atinge valores de 1200 $\mathrm{mm}$ e que valores inferiores são observados nos bairros da Zona Norte, o que está de acordo com os resultados aqui encontrados.

Nas Figuras $3 \mathrm{~b}$ a $3 \mathrm{e}$ apresentam-se a climatologia sazonal da precipitação. Os valores representam médias mensais em 


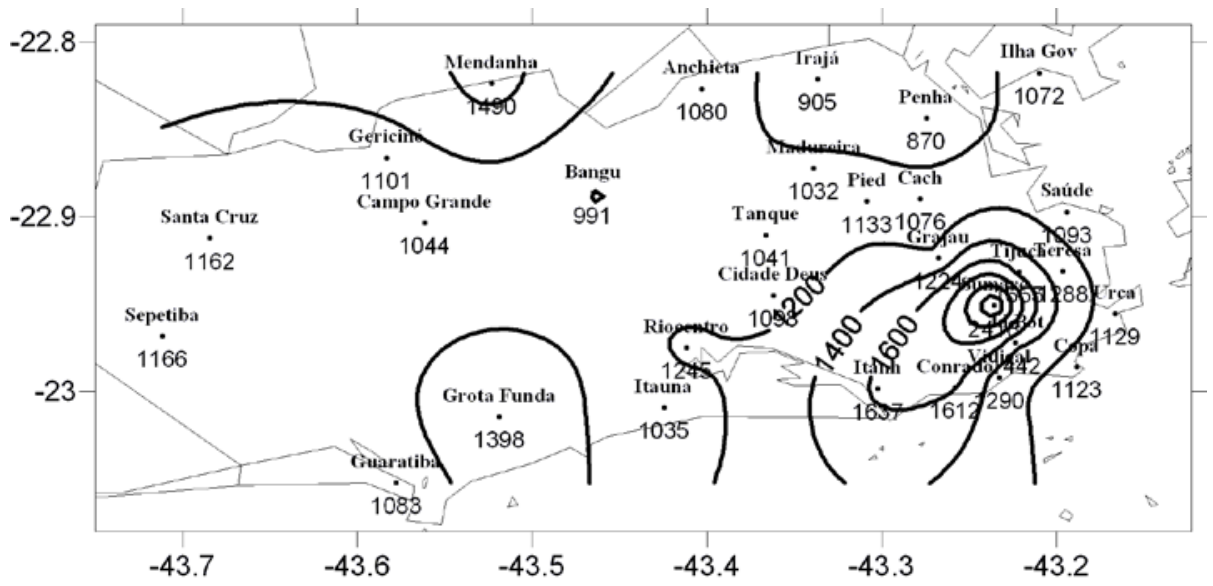

(a) Anual

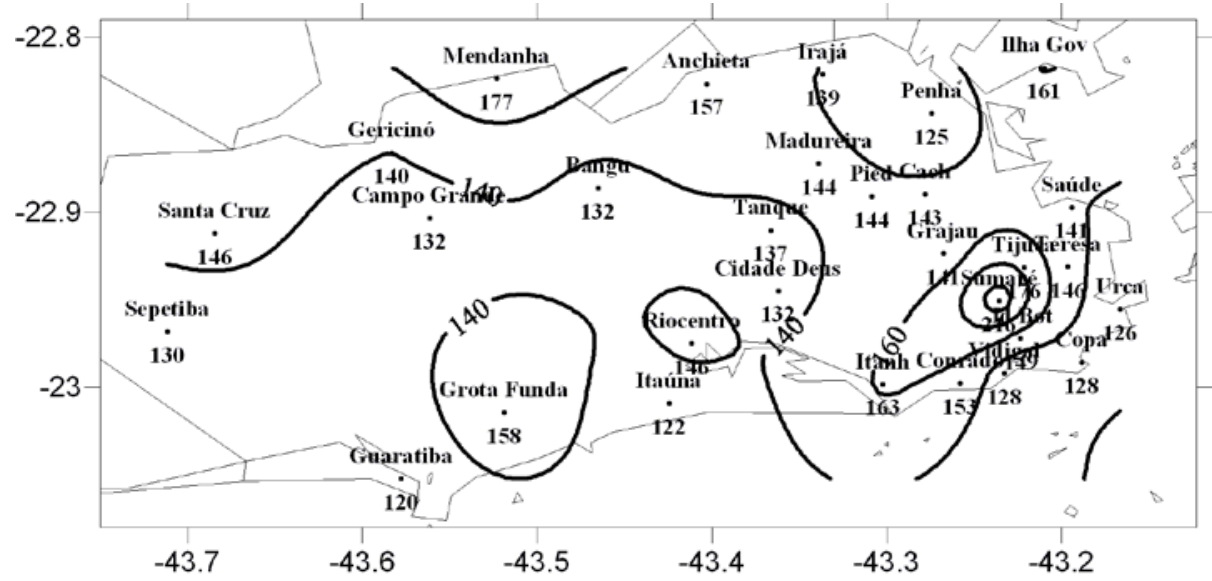

(b) Verão

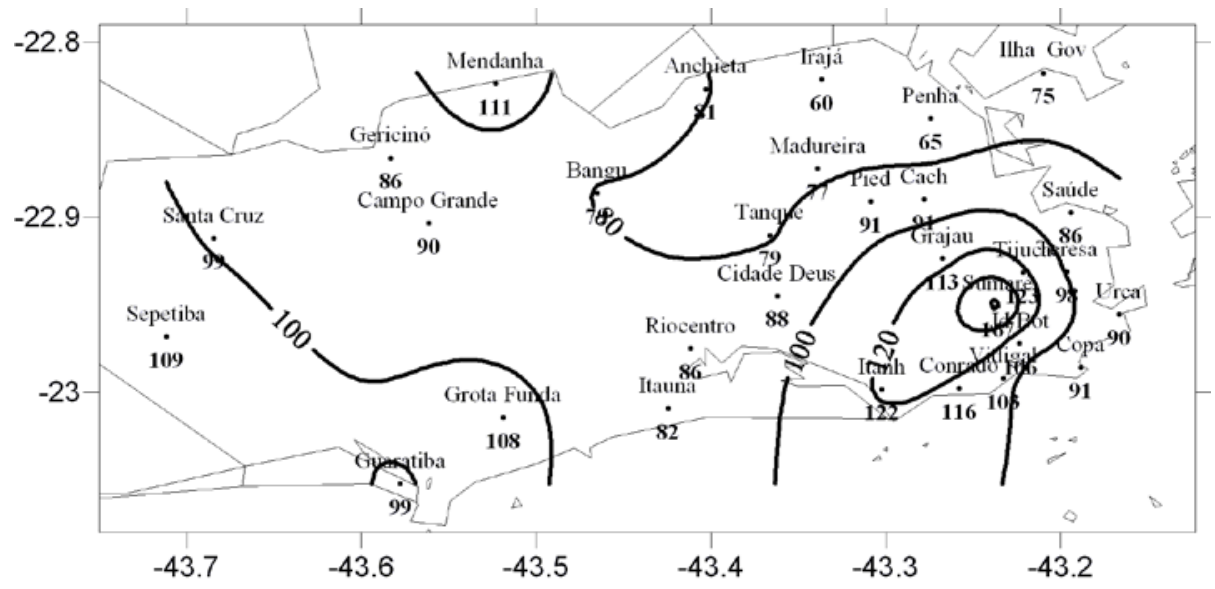

(c) Outono

Figura 3 - Precipitação no período 1997-2006. (a) totais anuais médios (contornos a cada 200 mm/ano), (b) totais mensais médios no verão (DJF), (c) totais mensais médios no outono (MAM), (d) totais mensais médios no inverno (JJA) e (e) totais mensais médios na primavera (SON), contornos a cada $20 \mathrm{~mm} / \mathrm{mês}$. 


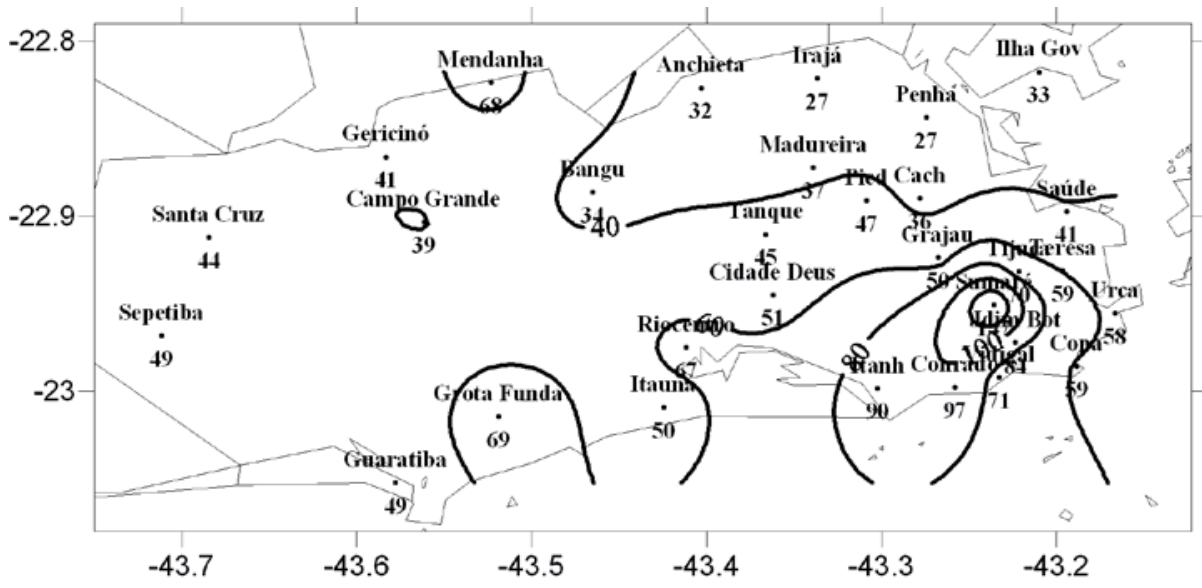

(d) Inverno

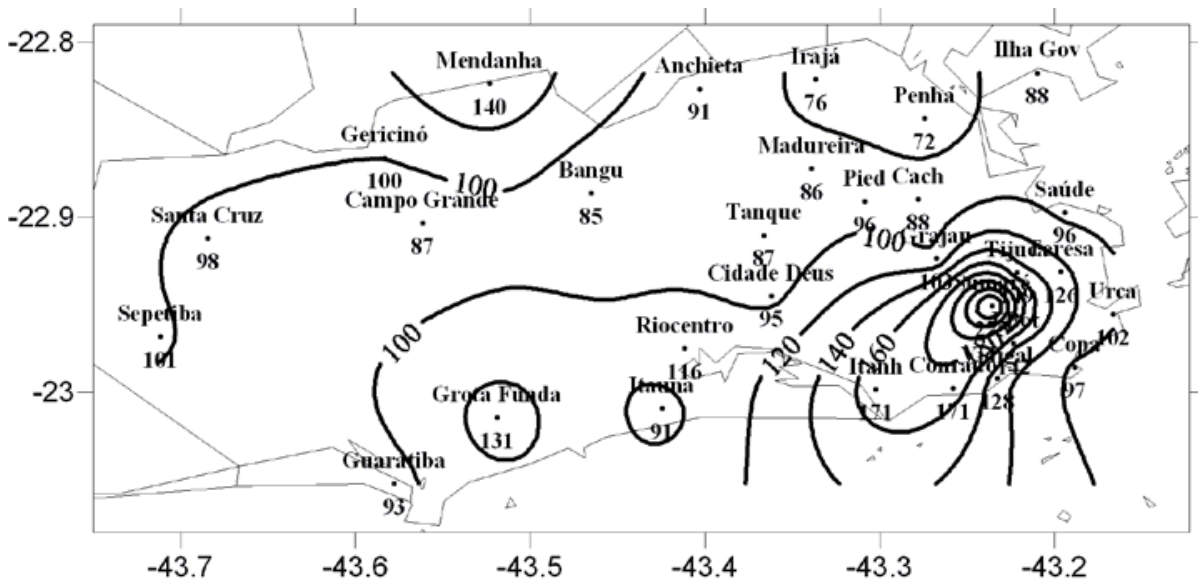

(e) Primavera

Figura 3 - Continuação

cada estação do ano. Durante o verão (Figura 3b), estação chuvosa, o total pluviométrico atinge uma média mensal de 200 mm próximo ao Sumaré. Próximo à estação Mendanha nota-se um máximo de $170 \mathrm{~mm}$ e na Grota Funda existe outro máximo de $150 \mathrm{~mm}$. No litoral sul (Vidigal, Urca e Copacabana), os valores de respectivamente 128,128 e 126 mm são inferiores aos observados em algumas estações da zona norte da cidade, como por exemplo em Madureira (144 mm), Piedade (144 mm) e Cachambi (143 mm), o que só ocorre nesta época do ano. Isto pode estar relacionado com o fato de que no verão a precipitação de caráter convectivo na área norte da cidade é intensificada pelo maior aquecimento local.

Na Figura 3c, referente ao outono, os máximos da Serra da Carioca $(160 \mathrm{~mm})$ e Serra do Mendanha $(100 \mathrm{~mm})$ são facilmente identificados, contudo os mesmos não ocorrem na Serra Geral de Guaratiba. No extremo norte da cidade, a precipitação é inferior às demais localidades, ressaltando-se os mínimos de $60 \mathrm{~mm}$ em Irajá e $65 \mathrm{~mm}$ na Penha. Na Zona Oeste a precipitação oscila entre 80 e $100 \mathrm{~mm}$, sendo que os valores se elevam no extremo oeste, chegando a $109 \mathrm{~mm}$ em Sepetiba.

No inverno (Figura 3d), estação seca, verifica-se um máximo de $130 \mathrm{~mm}$ na Serra da Carioca, e outros dois máximos de $60 \mathrm{~mm}$ na Serra do Mendanha e na Serra Geral de Guaratiba. Valores inferiores a $30 \mathrm{~mm}$ são observados no extremo norte da cidade, destacando-se a precipitação de apenas $27 \mathrm{~mm}$ na Penha e em Irajá.

$\mathrm{Na}$ Figura 3e, referente à primavera, nota-se um máximo proeminente de $250 \mathrm{~mm}$ na estação do Sumaré, sendo este máximo mais elevado do que no verão, e dois outros máximos de $140 \mathrm{~mm}$ na Serra do Mendanha e $130 \mathrm{~mm}$ na Serra Geral de Guaratiba. Nas áreas do extremo norte da cidade, predominam valores inferiores a $80 \mathrm{~mm}$. No oeste da cidade se encontram 
valores entre 90 e $100 \mathrm{~mm}$, destacando-se um mínimo de 87 mm em Campo Grande.

Os totais pluviométricos médios mensais para cinco estações pluviométricas selecionadas (Sumaré, Mendanha, Grota Funda, Santa Cruz e Penha) representativas, respectivamente das regiões localizadas na Serra da Carioca, Serra do Mendanha, Serra Geral de Guaratiba, Zona Oeste e Zona Norte são apresentados na Figura 4. Os totais pluviométricos mensais das demais estações do município não foram plotados para melhor visualização da figura, contudo tais curvas encontramse dispostas entre as curvas do Sumaré (local mais chuvoso) e da Penha (local menos chuvoso). A partir da Figura 4 torna-se evidente, que a chuva no Sumaré é muito mais intensa do que nas demais localidades. Apenas no mês de fevereiro o total pluviométrico médio mensal no Sumaré (143,5 mm) é inferior a alguma das demais estações pluviométricas, uma vez que se verifica 148,0 mm no Mendanha. Em setembro, por exemplo, a precipitação no Sumaré chega a ser $71 \%$ maior do que em São Conrado, que é segundo local mais chuvoso naquele mês e sete vezes maior do que em Irajá (local menos chuvoso em setembro).

Apesar do total pluviométrico médio anual no Mendanha ser superior ao observado na Grota Funda, os totais pluviométricos médios mensais nas duas localidades ao longo do ano são bem

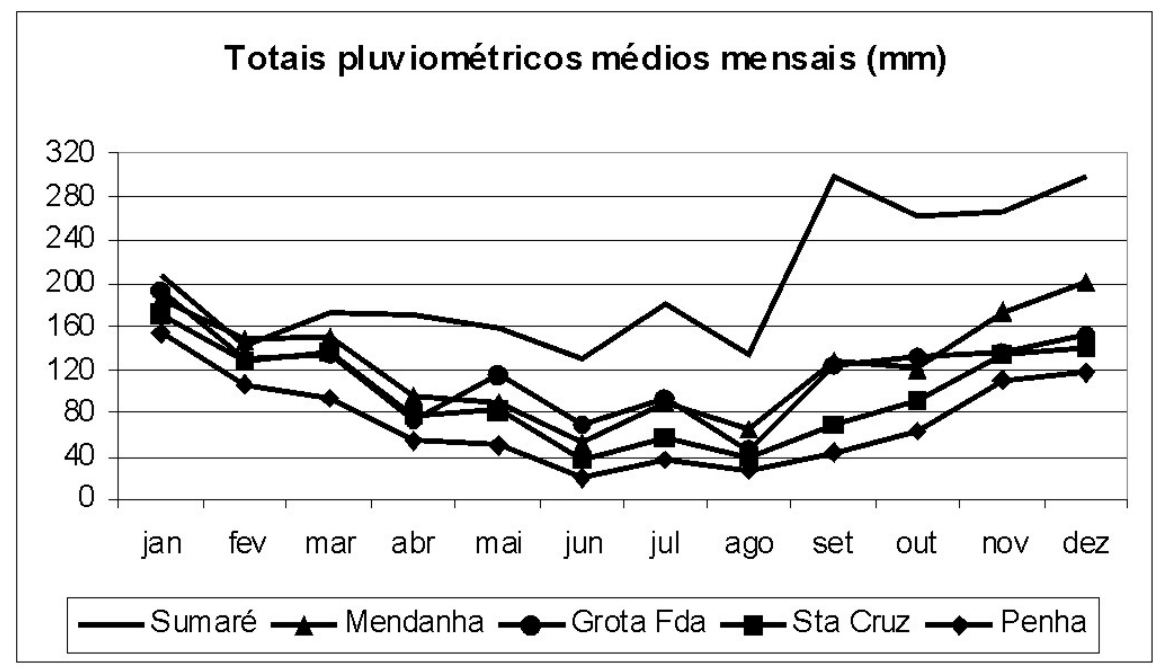

Figura 4 - Totais pluviométricos médios mensais (mm) na Serra da Carioca (Sumaré), na Serra do Mendanha (Mendanha), na Serra Geral de Guaratiba (Grota Funda), na Zona Oeste (Santa Cruz) e na Zona Norte (Penha).

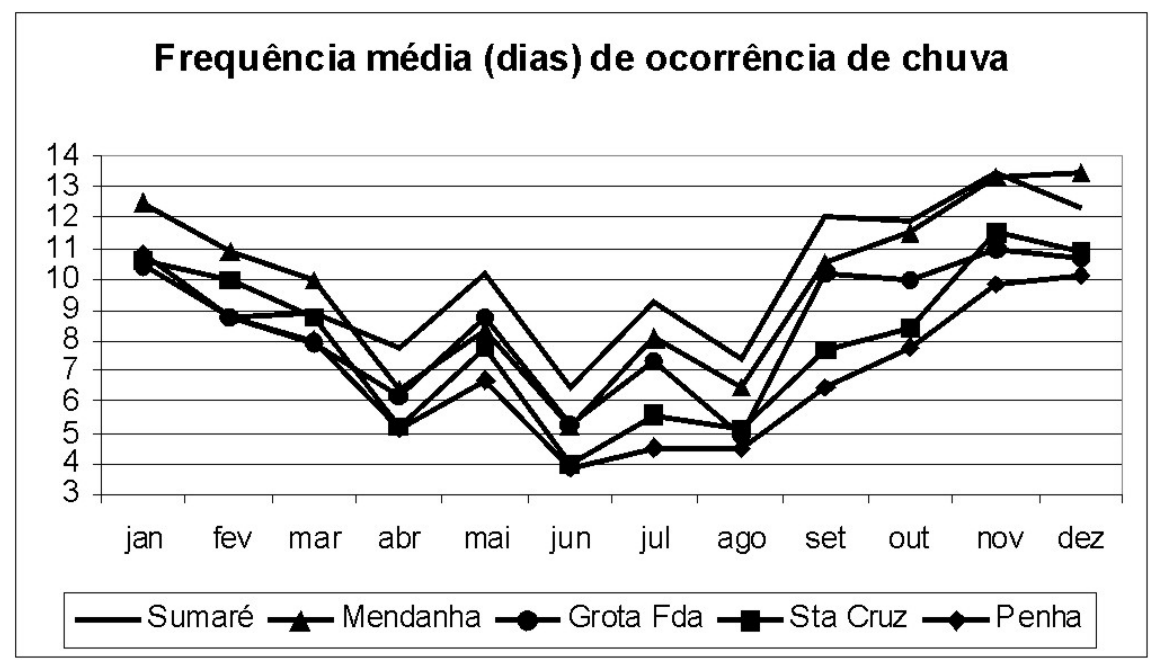

Figura 5 - Freqüência média (dias) de ocorrência de chuva (total pluviométrico diário maior ou igual a 1,0 mm) na Serra da Carioca (Sumaré), na Serra do Mendanha (Mendanha), na Serra Geral de Guaratiba (Grota Funda), na Zona Oeste (Santa Cruz) e na Zona Norte (Penha). 
próximos, exceto nos meses de novembro e dezembro, quando a chuva no Mendanha é mais intensa do que na Grota Funda. Como esperado, a precipitação na Penha é inferior às demais estações pluviométricas durante todo o ano. Nas cinco curvas apresentadas na Figura 4, nota-se uma elevação da precipitação em julho, em relação aos meses de junho e agosto. Contudo, tal aspecto não é verificado na climatologia do INMET (19611990) para a estação meteorológica do Aterro do Flamengo, onde nota-se de fato uma redução de junho $(80 \mathrm{~mm})$ para julho $(56 \mathrm{~mm})$ e a seguir para agosto $(51 \mathrm{~mm})$. De forma geral, para todos os postos pluviométricos analisados, o trimestre mais (menos) chuvoso é nov-jan (jun-ago).
Na Figura 5, apresenta-se a freqüência média de ocorrência de chuva (dias com total pluviométrico diário maior ou igual a $1 \mathrm{~mm}$ ). Nota-se que, coerentemente com os resultados da Figura 4, ao longo do ano são observados maior número de dias chuvosos no Sumaré (119 dias), a seguir no Mendanha (117 dias), Grota Funda (101 dias), Santa Cruz (96 dias) e por último na Penha (86 dias). Nas demais estações do Rio de Janeiro, a freqüência média de ocorrência de chuva está situada entre as curvas delimitadas pelo Mendanha e pela Penha. Como esperado, a freqüência de dias com ocorrência de precipitação decai do verão para o inverno e volta a subir na primavera.

Com relação à distribuição sazonal da precipitação ao

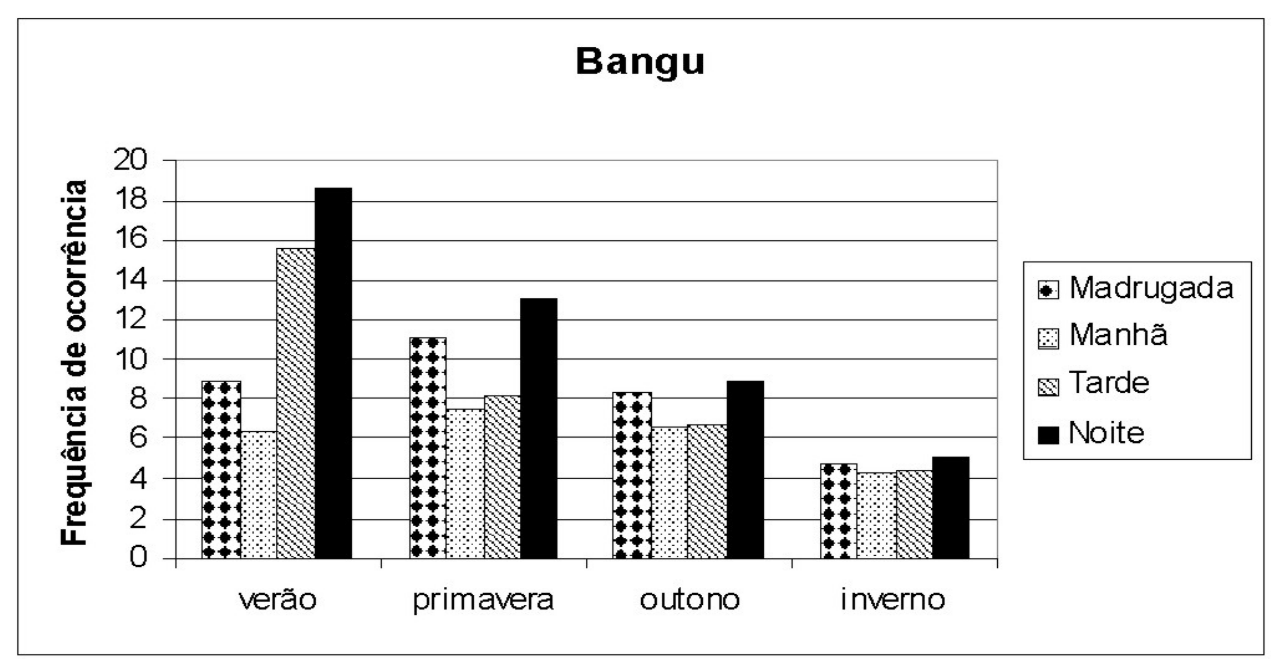

Figura 6 - Freqüência de ocorrência de eventos de chuva (total pluviométrico maior ou igual a $1 \mathrm{~mm})$ nos períodos da madrugada (0-6 h), manhã (6-12 h), tarde (12-18 h) e noite (18-0 h) em Bangu. Valores médios entre o outono de 1997 e a primavera de 2006.

\section{Máximos pluviométricos (mm)}

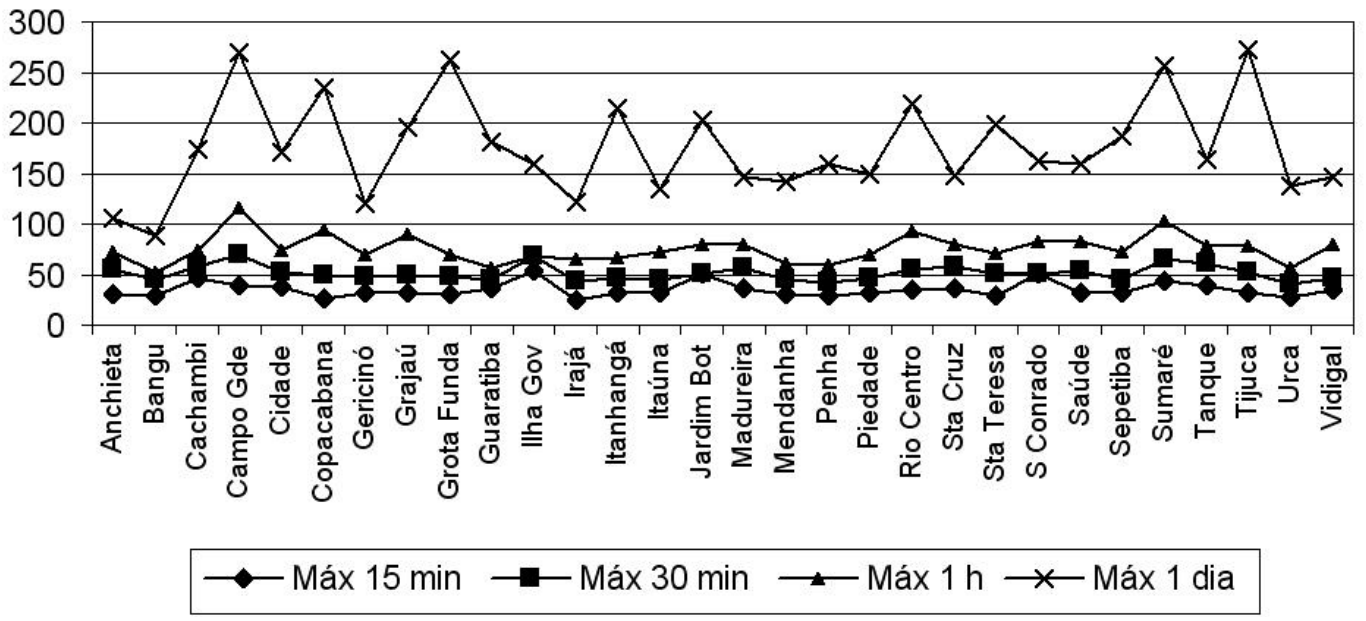

Figura 7 - Totais pluviométricos máximos (mm) em 15 e 30 minutos, 1 hora e 1 dia para as estações da Geo-Rio no período de 1997 a 2006. 
longo do ano, pode-se dizer que na maior parte dos postos pluviométricos o verão é a estação mais chuvosa, seguida da primavera, depois o outono e por último o inverno. Contudo, nas estações São Conrado e Sumaré a primavera é mais chuvosa do que o verão e no Cachambi, Campo Grande, Grajaú, Guaratiba, Santa Cruz e Sepetiba chove em média mais no outono do que na primavera.

Uma análise da distribuição da precipitação ao longo do dia foi elaborada considerando-se a freqüência de ocorrência da precipitação (total pluviométrico maior ou igual a $1 \mathrm{~mm}$ ) nos períodos da madrugada (0 - $6 \mathrm{~h})$, manhã (6 - $12 \mathrm{~h})$, tarde $(12-18 \mathrm{~h})$ e noite $(18-0 \mathrm{~h})$, sazonalmente. Este estudo foi realizado para todos os postos pluviométricos, contudo como as principais características são comuns a todos, selecionou-se apenas uma localidade para apresentação dos resultados. A Figura 6 apresenta os resultados da freqüência de ocorrência da precipitação ao longo do dia e sazonalmente para a localidade de Bangu.

Os resultados desta etapa da pesquisa mostram que no verão e primavera existe uma tendência de concentração dos eventos de chuva no período noturno, e uma baixa freqüência de ocorrência no período da manhã. Na maior parte das localidades ocorre concentração dos eventos nos períodos tarde/noite (noite/madrugada) durante o verão (primavera). Isto pode ser explicado devido ao maior aquecimento local nesta época do ano, com formação de nebulosidade convectiva no final da tarde e influência da brisa marítima, que no verão/primavera encontrase mais intensa, favorecendo a convergência de umidade para o interior do continente. No outono e inverno nota-se, assim como esperado, uma redução na freqüência de ocorrência dos eventos e também uma distribuição mais homogênea de tais eventos ao longo do dia. Para Bangu, por exemplo, enquanto $37 \%$ dos eventos de verão concentram-se no período noturno e apenas $13 \%$ no período da manhã, no inverno $27 \%$ ocorrem a noite, $26 \%$ na madrugada, $24 \%$ ocorrem a tarde e $23 \%$ na manhã. Tal distribuição homogênea da freqüência de ocorrência da precipitação durante o inverno está associada com a passagem de SFs, que predominam nesta época do ano e que não apresentam um horário preferencial de ocorrência.

\subsection{Taxas de Chuvas Intensas}

Os totais pluviométricos máximos acumulados em 15 e 30 minutos, 1 hora e 1 dia foram determinados para cada posto pluviométrico (Figura 7). Nota-se que a variabilidade espacial dos máximos de precipitação aumenta com o período de acumulação da chuva. A precipitação máxima totalizada em 15 minutos, mantém-se em média na área (considerando todas as estações pluviométricas) em torno de $35 \mathrm{~mm}$, com um desvio padrão de $7 \mathrm{~mm}$. Em 30 minutos, a precipitação máxima média na área do Rio de Janeiro sobe para $51 \mathrm{~mm}$, com um desvio padrão também de $7 \mathrm{~mm}$. Os máximos totalizados em 1 hora apresentam média na área em torno de $75 \mathrm{~mm}$ e desvio padrão de $13 \mathrm{~mm}$. Finalmente, os máximos diários ficam em torno de $174 \mathrm{~mm}$, com um desvio padrão de $47 \mathrm{~mm}$.

É importante ressaltar que diversos máximos apresentados na Figura 7 ocorreram durante os mesmos eventos, como por exemplo os máximos diários registrados na Grota Funda (263,0 mm), Itanhangá (214,3 mm), Jardim Botânico (203,0 mm), Rio Centro (218,6 mm), e Tijuca (272,8 mm), todos registrados em 09/01/98. Durante este mesmo evento registraram-se ainda os máximos de 15 minutos em Anchieta (31,1 mm - 07/01/98),

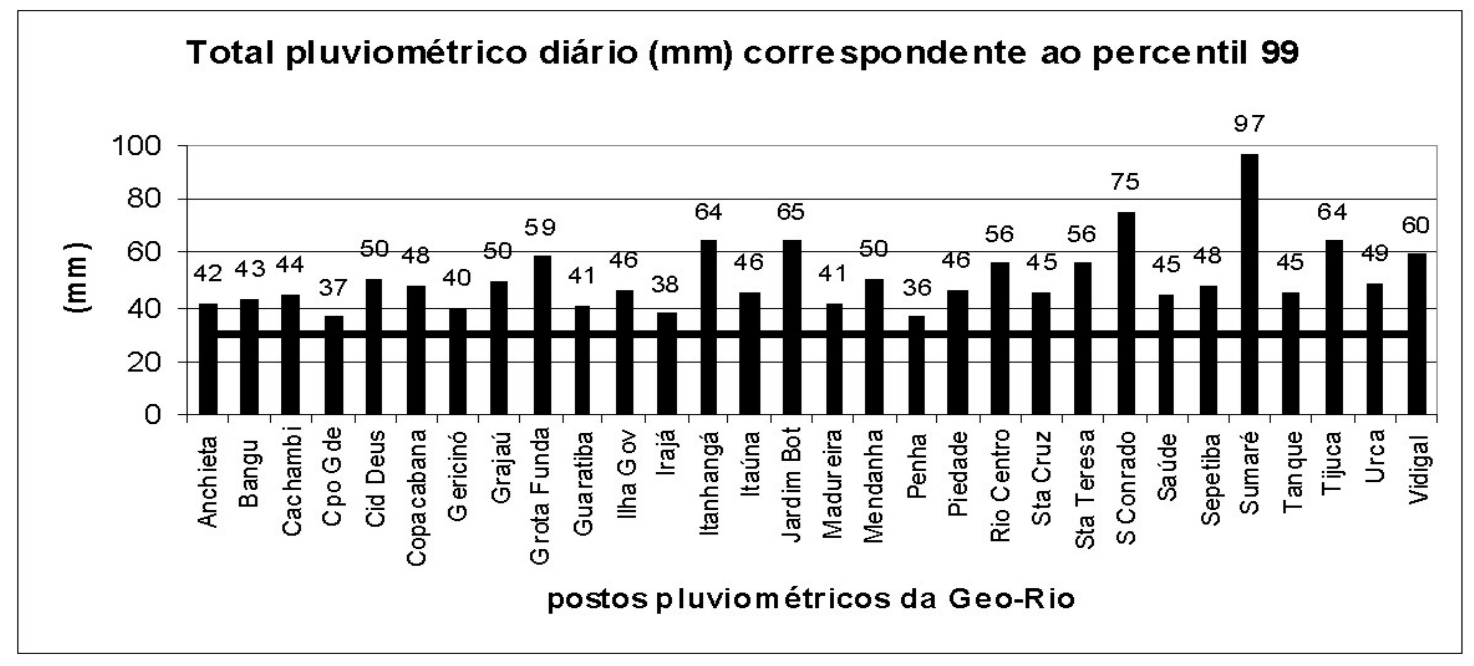

Figura 8 - Totais pluviométricos diários (mm) correspondentes ao percentil 99 para as estações da Geo-Rio no período de 1997 a 2006. 
Madureira (36,3 mm - 08/01/98) e Santa Teresa $(28,7 \mathrm{~mm}$ - 07/01/98), os máximos de 30 minutos $(51,1 \mathrm{~mm})$ e 1 hora $(70,3 \mathrm{~mm})$ em Santa Teresa e o máximo de 1 hora $(69,2 \mathrm{~mm})$ na Grota Funda em 08/01/98.

Para cada posto pluviométrico foram calculados percentis sobre os totais pluviométricos diários (Figura 8), com o objetivo de determinar um valor limite para classificação de eventos de chuvas intensas. Tal análise revelou que na Penha $1 \%$ dos totais pluviométricos diários (percentil 99) é superior a 34,7 mm, enquanto no Sumaré este valor alcança $92,3 \mathrm{~mm}$, o que mostra a grande variabilidade da precipitação no município. Para todas as estações pluviométricas a precipitação correspondente ao percentil 99 foi superior a $30,0 \mathrm{~mm}$, sendo, portanto, este limite adotado para seleção de eventos de chuvas intensas.

A seleção dos eventos de chuvas intensas foi elaborada, considerando-se os casos cujos totais pluviométricos diários em pelo menos 5 localidades fossem iguais ou superiores a 30,0 $\mathrm{mm}$. Desta forma foram selecionados 160 eventos ocorridos no período em estudo. A fim de ilustrar a pesquisada realizada, os dados relativos aos quinze eventos mais intensos são exibidos na Tabela 1. Para exemplificar, o caso mais extremo de chuvas intensas ocorreu nos dias 08 e 09 de janeiro de 1998.
Em ambos os dias as chuvas foram superiores a $30,0 \mathrm{~mm}$ em pelo menos 5 postos pluviométricos. No dia 09 de janeiro de 1998, que aparece em negrito na tabela, a chuva em cada um dos 30 postos ultrapassou o valor do percentil 99 estabelecido para cada localidade. Neste mesmo dia a precipitação média no município foi de $144,5 \mathrm{~mm}$, com máximo de $272,8 \mathrm{~mm}$ na Tijuca, acumulados entre $12: 15 \mathrm{Z}$ do dia 08 até $12: 00 \mathrm{Z}$ do dia 09 . Tal evento foi ocasionado pela aproximação e passagem de um sistema frontal, promovendo a formação de diversos SCMs desde o dia 6 até o dia 10 de janeiro de 1998.

A Figura 9 apresenta a estatística da freqüência de ocorrência dos sistemas meteorológicos associados aos 160 eventos de chuvas intensas ao longo do ano. Nota-se que, a maior parte dos casos de chuvas intensas (77\%) foi provocada por sistemas frontais (SFs). Tais sistemas ocorreram durante todo o ano, com uma queda acentuada em agosto (apenas 2 $\mathrm{SFs}$ ). A frequência de ocorrência de fenômenos de Zona de Convergência do Atlântico Sul (ZCAS) declinou de janeiro a março, sendo nula de abril a setembro e voltando a se elevar de outubro a dezembro. Os Sistemas Convectivos de Mesoescala (SCMs) ocorreram ao longo de todas as estações do ano, com declínio no inverno. Os casos de precipitação intensa

Tabela 1 - Seleção dos quinze eventos de precipitação mais intensos ocorridos no município do Rio de Janeiro, de janeiro de 1997 a dezembro de 2006.

\begin{tabular}{|c|c|c|c|c|}
\hline Data & $\begin{array}{l}\text { Prec. } \\
\text { Média } \\
\text { no } \\
\text { Município }\end{array}$ & $\begin{array}{l}\text { No. de postos } \\
\text { com total } \\
\text { pluviométrico } \\
\text { diário> } \\
\text { percentil } 99\end{array}$ & $\begin{array}{l}\text { Maior Total } \\
\text { Pluviométrico diário } \\
\text { (mm) - Localidade }\end{array}$ & $\begin{array}{l}\text { Fenômeno } \\
\text { Meteorológico }\end{array}$ \\
\hline $\begin{array}{c}08 \mathrm{e} \\
\mathbf{0 9 / 0 1 / 9 8}\end{array}$ & 144,5 & 30 & $272,8-$ Tijuca & $\begin{array}{c}\text { Aproximação e passagem de SF, } \\
\text { promovendo formação de diversos SCMs } \\
\text { desde o dia } 06 \text { até o dia } 10 / 01 / 98 \text {. }\end{array}$ \\
\hline $24 / 12 / 01$ & 125,6 & 30 & 252,8 - Sumaré & Passagem de SF, com formação de SCMs. \\
\hline $18 / 03 / 03$ & 109,9 & 29 & 186,6 - Sepetiba & $\begin{array}{l}\text { Passag em de SF, com formação de alguns } \\
\text { SCMs. }\end{array}$ \\
\hline $12 / 02 / 98$ & 97,8 & 28 & $263,6-$ Tijuca & $\begin{array}{l}\text { Passag em de SF, com formação de alguns } \\
\text { SCMs. A partir do evento, ZCAS ficou } \\
\text { configurada até dia } 16 / 02 / 98 \text {. }\end{array}$ \\
\hline $\begin{array}{c}02 \mathrm{e} \\
\mathbf{0 3 / 0 1 / 0 0}\end{array}$ & 72,7 & 23 & 180,9 - Guaratiba & ZCAS configurada de 01 a $08 / 01 / 00$. \\
\hline $24 / 05 / 06$ & 69,0 & 19 & 199,0 - Sumaré & $\begin{array}{l}\text { Passagem de SF, aparentemente sem } \\
\text { ocorrência de SCMs na região. }\end{array}$ \\
\hline $28 / 01 / 06$ & 68,8 & 21 & 113,8 - Saúde & ZCAS configurada entre $27 / 01$ e $02 / 02 / 06$ \\
\hline $17 / 02 / 00$ & 67,1 & 23 & 132,9 - Riocentro & $\begin{array}{l}\text { Passagem de SF, com formação de alguns } \\
\text { SCMs. }\end{array}$ \\
\hline $25 / 01 / 03$ & $\overline{64,4}$ & 13 & 235,4 - Copacabana & $\begin{array}{c}\text { Passag em de SF, com formação de alguns } \\
\text { SCMs. Após o evento ZCAS configurada até } \\
\text { dia } 01 / 02 / 03 \text {. }\end{array}$ \\
\hline $12 / 10 / 03$ & 62,8 & 25 & 137,2 - Sumaré & Passagem de SF. \\
\hline $18 / 04 / 06$ & 61,8 & $\overline{14}$ & 256,8 - Sumaré & Passagem de SF. \\
\hline $26 / 11 / 05$ & 61,1 & 19 & 93,0 - São Conrado & Passagem de SF. \\
\hline $07 / 04 / 03$ & 58,6 & 22 & 101,4- Rio Centro & Passagem de SF. \\
\hline $05 / 01 / 06$ & 52,5 & 12 & 97,6 - Gericinó & $\begin{array}{l}\text { ZCAS configurada entre } 01 \text { e } 08 / 01 / 06 . \mathrm{A} \\
\text { precipitação se intensific ou com a } \\
\text { aproximação de novos SFs na região. }\end{array}$ \\
\hline $19 / 03 / 00$ & 52,0 & 11 & 269,4-Campo Grande & $\begin{array}{l}\text { Passagem de SF, com formação de alguns } \\
\text { SCMs. }\end{array}$ \\
\hline
\end{tabular}


provocados por efeito de circulação marítima (CM) foram observados apenas em 4 eventos que ocorreram nos meses de abril, setembro, outubro e dezembro.

Com relação à distribuição interanual dos eventos intensos no período de 1997 a 2006 (Figura 10), nota-se uma maior freqüência de eventos em 1998 (25 casos) e menor freqüência em 2000 (apenas 10 eventos). Analisando-se a intensidade da precipitação durante os eventos de chuvas intensas, percebe-se também uma grande variabilidade interanual. Em determinados anos, as chuvas ocorridas nos eventos intensos não foram tão fortes como em outros anos. Em 1997, por exemplo, apenas dois eventos apresentaram máximos pluviométricos diários superiores a $100,0 \mathrm{~mm}$ e as precipitações médias no município ocorridas durante os eventos de chuvas intensas foram relativamente fracas, variando entre 12,9 e 31,3 $\mathrm{mm}$. Por outro lado, em 2003 ocorreram ao todo dez eventos com máximos pluviométricos diários superiores a 100,0 mm e as precipitações médias durante os eventos oscilaram entre 17,6 e 109,9 mm. A investigação sobre a grande variabilidade interanual, no que diz respeito à quantidade e a intensidade dos eventos não é foco deste estudo.

\section{CONCLUSÕES}

Este trabalho produziu uma climatologia da precipitação no município do Rio de Janeiro, a partir do conjunto de 10 anos

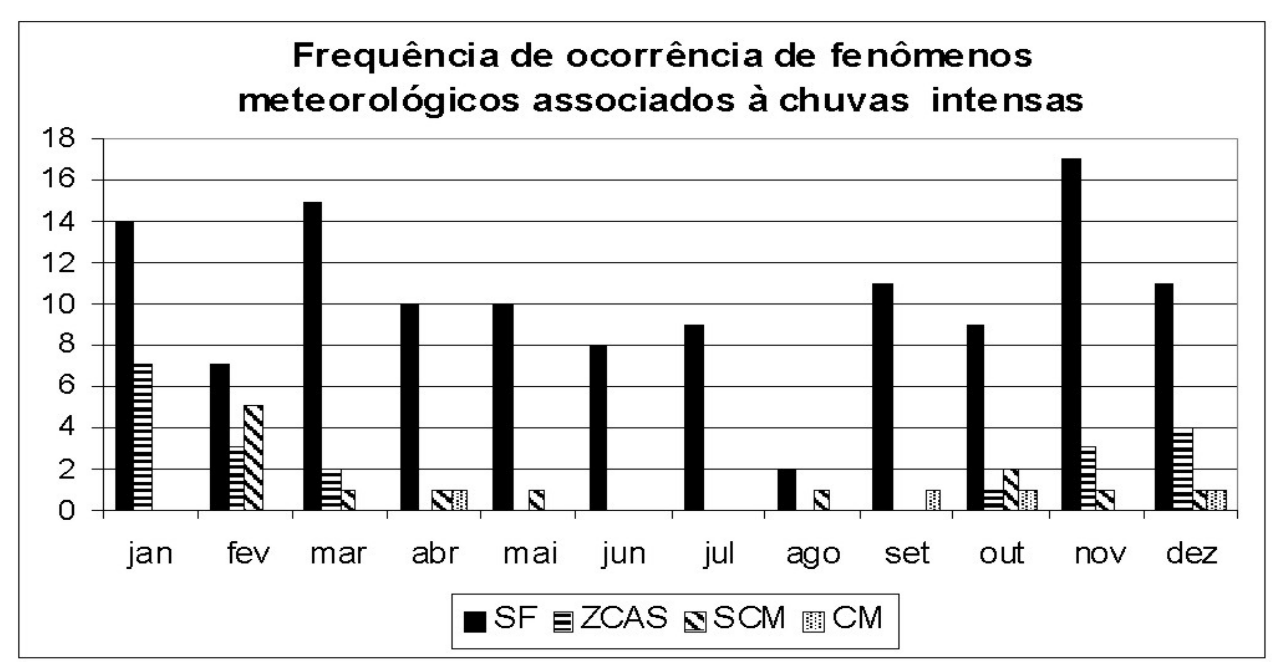

Figura 9 - Freqüência de ocorrência mensal de fenômenos meteorológicos associados aos eventos de chuvas intensas.

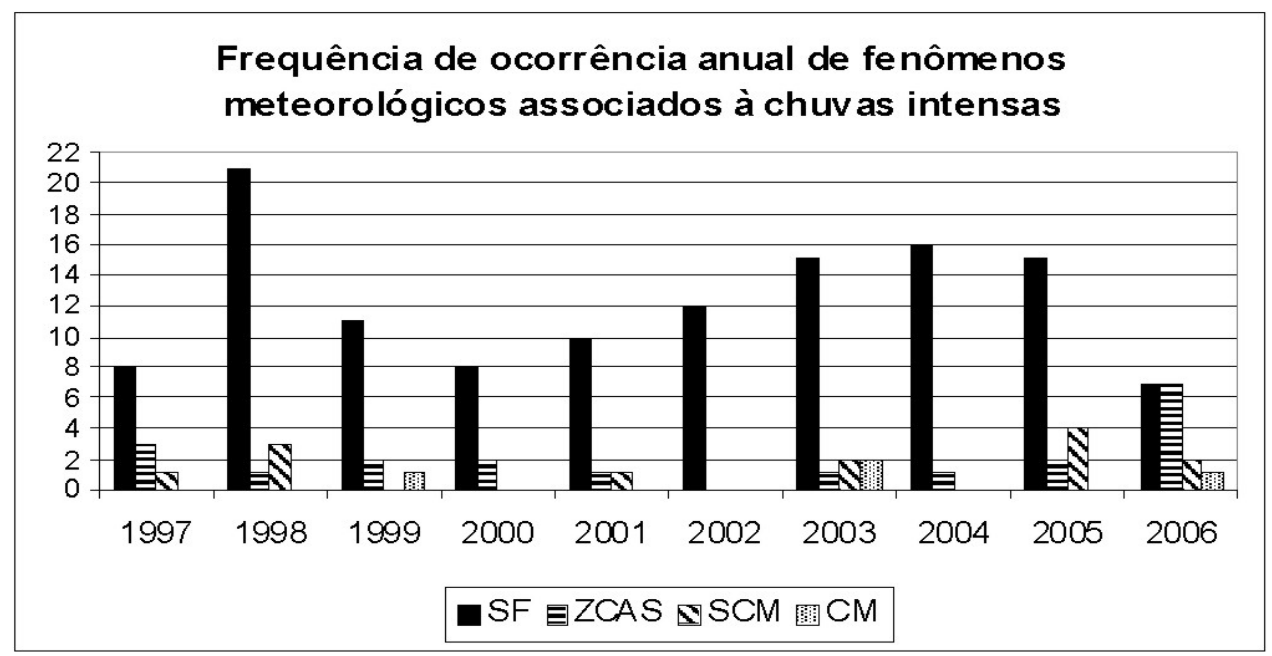

Figura 10 - Freqüência de ocorrência anual de fenômenos meteorológicos associados aos eventos de chuvas intensas. 
de dados (1997-2006) coletados em 30 estações pluviométricas da Fundação Geo-Rio.

As análises indicaram que ao longo do ano e sazonalmente os máximos de precipitação localizam-se sobre os três maciços existentes na cidade: Maciço da Tijuca (a leste), Maciço de Gericinó (ao norte) e Maciço da Pedra Branca (a oeste). Com relação aos totais pluviométricos anuais, os máximos são observados respectivamente, nas estações do Sumaré (2200 $\mathrm{mm})$, do Mendanha (1400 mm) e da Grota Funda (1200 mm). Na Zona Norte da cidade verifica-se um mínimo de precipitação, com $905 \mathrm{~mm}$ em Irajá e $870 \mathrm{~mm}$ na Penha. Nas demais áreas de planície da cidade, a precipitação distribui-se de forma homogênea, variando entre 1000 e $1200 \mathrm{~mm}$. Este padrão de distribuição espacial da precipitação é explicado pelos sistemas meteorológicos em deslocamento preferencialmente de sul para norte, produzindo máximos (mínimos) de precipitação à barlavento (sotavento) das serras. Tal processo é amplificado pelo levantamento de ar úmido trazido pela brisa marítima que predomina no município. No verão nota-se que a precipitação no litoral da Zona Sul (Vidigal, Urca e Copacabana) é inferior à observada na Zona Norte da cidade, como por exemplo em Madureira, Piedade e Cachambi, o que só ocorre nesta época do ano. Isto pode estar relacionado com o fato de no verão a precipitação de caráter convectivo na área norte da cidade ser intensificada pelo maior aquecimento local.

A análise dos totais pluviométricos mensais ao longo do ano para todos os postos pluviométricos revela que no Sumaré chove muito mais do que nas demais localidades ao longo de praticamente todo o ano, chegando a precipitação média mensal em setembro ser sete vezes maior que na Penha. No Sumaré, além das chuvas serem mais intensas do que nas demais localidades, ocorre constante condensação de vapor d'água nas paredes do pluviômetro, o que contribui para um aumento do total pluviométrico mensal (Moraes, comunicação pessoal). De forma geral, para todos os postos pluviométricos analisados, o trimestre mais (menos) chuvoso é nov-jan (jun-ago).

Da análise dos dias chuvosos (total pluviométrico diário maior ou igual a $1 \mathrm{~mm}$ ), verifica-se que ao longo do ano são observados maior número de dias chuvosos no Sumaré (119 dias) e menor na Penha (86 dias). Como esperado, a freqüência de dias com ocorrência de precipitação decai do verão para o inverno e volta a subir na primavera.

Os resultados da análise da freqüência de ocorrência da precipitação (total pluviométrico maior ou igual a $1 \mathrm{~mm}$ ) ao longo do dia e sazonalmente sugerem que no verão (primavera), os eventos de precipitação concentram-se nos períodos da noite/tarde (noite/madrugada) associados ao caráter convectivo da precipitação, que desenvolve-se preferencialmente no final da tarde, influenciada provavelmente pelo maior aquecimento local e pela intensificação da brisa marítima, que aumenta a convergência de umidade no interior do município. A influência das brisas terrestre/marítima na distribuição espacial e temporal da precipitação sobre o município, merece uma investigação detalhada a partir de estudos com modelagem numérica regional. Por outro lado, no outono/inverno os eventos de chuva são distribuídos de forma mais uniforme ao longo do dia, associados com a penetração de SFs, não apresentando um período preferencial de ocorrência.

Os totais pluviométricos máximos em 15 e 30 minutos, 1 hora 1 dia foram determinados para cada estação pluviométrica, ficando em média para toda cidade em torno de respectivamente $35,51,75$ e $174 \mathrm{~mm}$

Uma análise dos eventos de chuvas intensas (totais pluviométricos diários superiores a $30,0 \mathrm{~mm}$ em pelo menos 5 estações pluviométricas) indicou que a maior parte dos casos de chuvas intensas $(77 \%)$ foi provocada por sistemas frontais (SFs). Tais sistemas ocorreram durante todo o ano, com uma queda acentuada em agosto (apenas $2 \mathrm{SFs}$ ). A frequência de ocorrência de fenômenos ZCAS (13\%) declinou de janeiro a março, sendo nula de abril a setembro e voltando a se elevar de outubro a dezembro. Os SCMs (8\%) ocorreram ao longo de todas as estações do ano, com declínio no inverno. Os casos de precipitação intensa provocados por $\mathrm{CM}(2 \%)$ foram observados apenas em 4 eventos que ocorreram nos meses de abril, setembro, outubro e dezembro. Com relação à distribuição anual de tais eventos intensos, nota-se uma grande variabilidade na freqüência de ocorrência dos mesmos, sendo a maior freqüência de eventos em 1998 ( 25 casos) e menor freqüência em 2000 (apenas 10 eventos).

Em que pese o fato de que este estudo analisou um período de tempo relativamente pequeno de dados (10 anos), portanto, sendo algo limitado em relação às normais climatológicas de 30 anos, de qualquer forma pode-se afirmar que esta climatologia preliminar da precipitação na cidade do Rio de Janeiro é útil para trabalhos futuros, por exemplo de planejamento urbano.

\section{AGRADECIMENTOS}

As autoras agradecem à Fundação Geo-Rio pelo fornecimento dos dados e ao Conselho Nacional de Desenvolvimento Científico e Tecnológico (CNPq) pelo suporte financeiro através da Bolsa de Apoio Técnico (Processo número 503869/2005-8) concedida à segunda autora.

\section{REFERÊNCIAS BIBLIOGRÁFICAS}

DOMINGUES, I. P.; DERECZYNSKI, C. P. Estudo de Caso de Chuva no Rio de Janeiro por efeito de circulação marítima. In: CONGRESO ARGENTINO DE METEOROLOGIA, 9 , 
Buenos Aires, 2005. Anais... Buenos Aires: Centro Argentino de Meteorólogos, 2005. 1 CD-ROM.

FUNDAÇÃO INSTITUTO DE DESENVOLVIMENTO ECONÔMICO E SOCIAL DO RIO DE JANEIRO. Indicadores Climatológicos do Estado do Rio de Janeiro. Governadoria do Estado do Rio de Janeiro, Secretaria de Planejamento e Coordenação Geral (SECPLAN), Fundação Instituto de Desenvolvimento Econômico e Social do Rio de Janeiro (FIDERJ). Sistemas de Informação para o Planejamento Estadual (SIPE), 1978. Rio de janeiro, 1978. $156 \mathrm{p}$.

INSTITUTOBRASILEIRODEGEOGRAFIAEESTATÍSTICA. Banco de Dados. Cidades. Disponível em $<\mathrm{http} / / / \mathrm{www} . i b g e$. gov.br/cidadesat $>$. Acesso em: 20 jul. 2007.

INSTITUTO PEREIRA PASSOS. Anuário Estatístico da Cidade do Rio de Janeiro, Prefeitura da Cidade do Rio de Janeiro. Disponível em: <http://www.armazemdedados.rio.rj.gov. br/>. Acesso em: 15 ago. 2007.

JOURDAN, P. Caracterização do regime de ventos próximo à superfície na Região Metropolitana do Rio de Janeiro. Trabalho (Monografia em meteorologia) - Departamento de Meteorologia do Instituto de Geociências. Rio de Janeiro: Universidade Federal do Rio de Janeiro, 2007.

JUNKER, N. W.; SCHNEIDER, R. S.; FAUVER, S. L. A study of heavy rainfall events during the great Midwest flood of 1993. Weather and Forecasting, v. 14, p. 701-712, 1999.

JUSTI DA SILVA, M. G. A. A Freqüência de Fenômenos Meteorológicos na América do Sul: Climatologia e Previsibilidade. Tese (Doutorado em engenharia mecânica) - Coordenação dos Programas de Pós Graduação em Engenharia. Rio de Janeiro: Universidade Federal do Rio de Janeiro, 2003.

KALNAY, E.; KANAMITSU, M.; KISTLER, R.; COLLINS, W.; DEAVEN, D.; GADIN, L.; IREDELL, M.; SAHA, S.; WHITE, G.; WOOLEN, J.; ZHU, Y.; CHELLIAH, M.; EBISUZAKI, W.; HIGGINS, W.; JONAWIAK, J.; MO, K.C.; ROPELEWISK, C.; WANG, J.; LEETMAA, A.; REYNOLD, R.; JENNE, R.; JOSEPH, D. The NCEP/NCAR 40 - Year Reanalysis Project. Bulletin of the Meteorological Society, v.77, p. 437-471, 1996.

KODAMA, Y. Large-Scale Common Features of Subtropical Precipitation Zones (the Baiu Frontal Zones, the SPCZ, and the SACZ) Part I: Characteristics of Subtropical Frontal Zones. Journal of Meteorological Society of Japan, v. 70, n.4, p. 813-835, 1992.

KONRAD II, C. E. Synoptic-scale features associated with warm season heavy rainfall over the interior southern United States. Weather and Forecasting, v. 12, p. 557-571, 1997.

KOUSKY, V. E. Pentad Outgoing Longwave Radiation Climatology for the South American Sector. Revista Brasileira de Meteorologia, v. 3, p. 217-231, 1988.

LEMOS C. F.; CALBETE, N. O. Sistemas Frontais que atuaram no litoral de 1987 a 1995. Climanálise Especial, Edição Comemorativa de 10 anos. Disponível em: $<\mathrm{http}: / / \mathrm{www}$. cptec.inpe.br/products/climanalise/cliesp10a/index1.shtml $>$. Acesso em: 11 ago. 2007.

LIEBMANN, B.; JONES, C.; CARVALHO, L. M. V. DE. Interannual variability of daily extreme precipitation events in the State of São Paulo, Brazil. Journal of Climate, v. 14, p. 208-218, 2000.

MMA - MINISTÉRIO DO MEIO AMBIENTE. Relatório Ambiental Urbano Integrado. Disponível em: $<\mathrm{http}: / / \mathrm{www}$. mma.gov.br/port/sqa/urbana/>. Acesso em: 15 mar. 2007.

NOBRE, C. A.; MATTOS, L. F.; DERECZYNSKI, C. P.; TARASOVA, T. A.; TROSNIKOV, I.V. Overview of atmospheric conditions during the Smoke, Clouds, and Radiation-Brazil (SCAR-B) field experiment. Journal of Geophysical Research, v. 103, n. D24, p. 31809-31820, 1998.

OLIVEIRA, A. Interações entre sistemas frontais na América do Sul e a convecção da Amazônia. Dissertação (Mestrado em meteorologia) - Instituto Nacional de Pesquisas Espaciais. São José dos Campos: Instituto Nacional de Pesquisas Espaciais, 1986.

SERRA, A. B. Clima da Guanabara. Boletim Geográfico, ano 29, n. 214, jan/fev 1970, Fundação Instituto Brasileiro de Geografia, p. 80-111, 1970.

SERRA, A. B.; RATISBONNA L. Clima do Rio de Janeiro. 2. ed., Transcrição de: Boletim Geográfico. Ministério da Agricultura. Serviço de Meteorologia, p. 527-560, 1957.

TEIXEIRA, M. S.; SATYAMURTY, P. Dynamical and synoptic characteristics of heavy rainfall episodes in southern Brazil. Monthly Weather Review, v. 135, p. 598-617, 2007.

VIANELLO, R. L.; ALVES, A. R. Meteorologia básica e aplicações. Viçosa; Imprensa Universitária, 1991. Universidade Federal de Viçosa. Imprensa Universitária, 1991. p. 330-331. 